\title{
Change in cough reflex after treatment with enalapril and ramipril
}

\author{
J R McEwan, N Choudry, R Street, R W Fuller
}

Abstract

Objective-To find out whether enalapril or ramipril causes the sensitivity of the cough reflex to change or symptomatic cough to develop in patients with hypertension.

Design-Prospective, placebo controlled, double blind, randomised crossover study.

Setting-Academic units of clinical pharmacology and medicine.

Patients - 20 Patients (nine men and 11 women) who needed to take angiotensin converting enzyme inhibitors to control hypertension.

Interventions - All patients received enalapril 10 $\mathrm{mg}$ daily, ramipril $10 \mathrm{mg}$ daily, or placebo daily for one week in random order, with a washout period of at least one week between treatments. For assessment of sensitivity of the cough reflex the patients inhaled various concentrations of capsaicin solution in random order.

Main outcome measures-Measurement of the doses of capsaicin required to cause two or more and five or more coughs or the development of a symptomatic cough.

Results-Blood pressure, symptoms of cough, and the sensitivity of the cough reflex to inhaled capsaicin were recorded at the start of the study and before and at the end of each treatment period. Plasma urea and creatinine concentrations and angiotensin converting enzyme activity were measured at the start of the study and the end of each treatment period. Data were analysed by two way analysis of variance. Mean blood pressure was $159 / 97 \mathrm{~mm} \mathrm{Hg}$ at the start of the study and $152 / 92,143 / 88$, and $147 / 86 \mathrm{~mm} \mathrm{Hg}$ after treatment with placebo, enalapril, and ramipril respectively. Mean (SE) plasma angiotensin converting enzyme activity was $2 \cdot 2(0.2) \mathrm{mmol} / \mathrm{l} / \mathrm{h}$ after treatment with placebo and fell significantly to $1.3(0.1) \mathrm{mmol} / \mathrm{l} / \mathrm{h}$ and to $0.4(0.1) \mathrm{mmol} / \mathrm{l} / \mathrm{h}$ after treatment with enalapril and ramipril respectively. No patient complained of cough while taking placebo but three women complained of cough when taking both enalapril and ramipril. The mean $(95 \%$ confidence interval) lowest dose of capsaicin causing two or more coughs was $2.4(1.5$ to 4.0$), 1.8(1.12$ to 2.82$)$, and $2.2(1.7$ to 3.0$) \mathrm{nmol}$ after treatment with placebo, enalapril, and ramipril respectively; none of these changes were significant. The lowest dose of capsaicin causing five or more coughs was 18.9 (13.9 to $25 \cdot 8), 14.4(8.4$ to 24.5$)$, and $15.3(10.8$ to 21.2$)$ nmol respectively; none of these changes were significant. The three patients who complained of cough had normal sensitivity to capsaicin after treatment with placebo but had a considerably increased sensitivity after treatment with enalapril and ramipril.

Conclusions - Both enalapril and ramipril increase the sensitivity of the cough reflex appreciably in patients who complain of cough during treatment, but they do not change the sensitivity in all patients who need to take angiotensin converting enzyme inhibitors.

\section{Introduction}

Angiotensin converting enzyme inhibitors are used extensively to treat both hypertension and heart failure. In general these drugs are well tolerated, and they reduce mortality from and improve symptoms of severe congestive cardiac failure and improve myocardial function after a myocardial infarction. ${ }^{12}$ Several workers have reported the unusual side effect of cough associated with treatment with angiotensin converting enzyme inhibitors. ${ }^{3-6}$ The estimated incidence varies and is thought to be between $1 \%$ and $14 \% .^{7.9}$

We have developed a reproducible method for measuring the sensitivity of the cough reflex by testing the cough responses to different doses of inhaled capsaicin. ${ }^{1011}$ By this method we have shown that cough during treatment with angiotensin converting enzyme inhibitors is associated with an increase in the sensitivity of the cough reflex. ${ }^{11}$ Whether the cough is due to this in all patients treated with these drugs, with only a few patients developing symptoms, or to the susceptibility of some patients to cough is unclear, although a small change in the cough response after a single dose of captopril occurred in all subjects in a study of normal volunteers. ${ }^{12}$ Nor is it known whether the cough is related to the degree of inhibition of plasma angiotensin converting enzyme activity or the reduction in blood pressure achieved by the drugs.

We examined the effect of two long acting, potent angiotensin converting enzyme inhibitors, enalapril and ramipril (ramipril is currently undergoing phase II and phase III clinical evaluation for treating heart failure and hypertension ${ }^{13}{ }^{14}$ ), on blood pressure, plasma angiotensin converting enzyme activity, and cough in a double blind crossover study.

\section{Methods}

The study was approved by the research ethics committee of Hammersmith and Queen Charlotte's Hospitals Special Health Authority. Twenty patients (nine men and 11 women) with a mean age of 54 (range 37-69) were studied. All of them required treatment with angiotensin converting enzyme inhibitors to control blood pressure. The table summarises the patients' characteristics. Those patients who were taking other antihypertensive drugs continued to take them throughout the study: 11 were taking a $\beta$ blocker, 14 a diuretic, and one a calcium channel blocker. Eleven of the patients were current smokers, two were asthmatic and inhaled $\beta$ adrenoceptor agonists regularly, one was a non-insulin dependent diabetic and one was an insulin dependent diabetic. One patient took prednisolone $5 \mathrm{mg}$ daily throughout the study for psoriatic arthritis and another took terfenadine $60 \mathrm{mg}$ twice daily for hay fever.
Correspondence to: $\mathrm{Dr}$ McEwan.

BrMed f 1989;299:13-6 
Characteristics of 20 patients who needed to take angiotensin converting enzyme inhibitors to control hypertension

\begin{tabular}{|c|c|c|c|c|}
\hline Case No & Age/Sex & Concurrent disease & Concurrent treatment & Current smoker \\
\hline 1 & $56 \mathrm{~F}$ & Hay fever & ß Blocker and terfenadine & No \\
\hline \multirow[t]{2}{*}{2} & $54 \mathrm{M}$ & Non-insulin dependent & $\beta$ Blocker & \\
\hline & $68 \mathrm{~F}$ & diabetes mellitus & $\beta$ Blocker and diuretic & No \\
\hline 4 & $69 \mathrm{M}$ & & Diuretic and calcium & Yes \\
\hline & & & channel blocker & Yes \\
\hline 5 & $62 \mathrm{~F}$ & & B Blocker and diuretic & Yes \\
\hline 6 & $42 \mathrm{~F}$ & & B Blocker and diuretic & Yes \\
\hline 7 & $56 \mathrm{M}$ & & $\beta$ Blocker and diuretic & No \\
\hline 8 & $63 \mathrm{~F}$ & $\begin{array}{l}\text { Insulin dependent } \\
\text { diabetes mellitus }\end{array}$ & Diuretic & No \\
\hline 9 & $64 \mathrm{~F}$ & & Diuretic & Yes \\
\hline 10 & $60 \mathrm{~F}$ & & Diuretic & Yes \\
\hline 11 & $60 \mathrm{~F}$ & & $\beta$ Blocker and diuretic & Yes \\
\hline 12 & $65 M$ & Asthma & & Yes \\
\hline 13 & $42 \mathrm{~F}$ & Arthritis & Diuretic and prednisolone & Yes \\
\hline 14 & $38 M$ & Asthma & & Yes \\
\hline 15 & $56 \mathrm{M}$ & & $\beta$ Blocker and diuretic & Yes \\
\hline 16 & $37 \mathrm{M}$ & & Diuretic & Yes \\
\hline 17 & $51 M$ & & ß Blocker and diuretic & No \\
\hline 18 & $54 \mathrm{M}$ & & $\beta$ Blocker and diuretic & No \\
\hline 19 & $55 \mathrm{M}$ & & B Blocker & No \\
\hline 20 & $56 \mathrm{~F}$ & & & No \\
\hline
\end{tabular}

Patients attended the clinical laboratory on six occasions at the same time of day. After baseline measurements of blood pressure, plasma urea and creatinine concentrations, and plasma angiotensin converting enzyme activity and the cough challenge test each patient received enalapril $10 \mathrm{mg}$ daily, ramipril $10 \mathrm{mg}$ daily, or placebo for one week, in random order, with a washout period of at least one week between each treatment period. The patients were instructed to take the capsules at night time. Compliance was measured by a pill count and plasma angiotensin converting enzyme activity. Plasma urea and creatinine concentrations and plasma angiotensin converting enzyme activity were measured at the end of each treatment period, whereas blood pressure and results of the cough challenge test were measured at the start and end of each treatment period. All measurements were taken in the morning. Patients were asked during each visit if they had developed a cough or other symptoms.

Blood pressure was measured in the sitting position during each visit after 15 minutes' rest with a Dinamap automatic pressure recorder. Two measurements were made 10 minutes apart and the mean of the two used in the analysis. Sensitivity of the cough reflex to inhaled capsaicin was measured during each visit. A $0.01 \mathrm{M}$ solution of capsaicin in absolute alcohol was diluted with $0.9 \%$ saline for inhalation. Patients inhaled single breaths $(0.02 \mathrm{ml})$ of the solution at doses of $0.4,0.8$, $1 \cdot 6,3 \cdot 2,6 \cdot 4,12 \cdot 5,25$, and $50 \mathrm{nmol}$ in random order from a nebuliser controlled by a dosimeter ( $P$ K Morgan, United Kingdom) unless the cough became excessive. The patients were unaware of the concentration of capsaicin in each inhalation. Coughs were recorded by a microphone connected to a mingograf recorder (Siemen-Elema AB, Solna, Sweden) that was running at $25 \mathrm{~mm} / \mathrm{s}$. Figure 1 shows the lowest tested doses of capsaicin that caused two or more and five or more coughs.

Blood samples were taken at the start of the study and at the end of each treatment period to measure urea and electrolyte concentrations. Blood was also taken and centrifuged immediately and the plasma stored for subsequent analysis of angiotensin converting enzyme activity by fluorimetry. ${ }^{15}$

Data from all six visits were analysed by a two way analysis of variance. For the cough reflex sensitivity this was performed on the transformed logarithmic values of the lowest doses of capsaicin causing at least two and five coughs. Blood pressure, urea and creatinine concentrations, and plasma angiotensin converting enzyme activity were expressed as mean (SE) values and the doses of capsaicin causing at least two and five coughs as geometric means $(95 \%$ confidence intervals).

\section{Results}

No significant difference was found in blood pressure at the start of each treatment period: the mean (SE) blood pressure was 159 (3)/97 (2), 154 (3)/93 (2), and 154 (3)/95 (2) $\mathrm{mm} \mathrm{Hg}$ respectively. There was no significant change in blood pressure after treatment with placebo $(152(4) / 92(3) \mathrm{mm} \mathrm{Hg})$. Blood pressure was $143(3) / 88$ (2) $\mathrm{mm} \mathrm{Hg}$ after treatment with enalapril and 147 (4)/86 (3) $\mathrm{mm} \mathrm{Hg}$ after treatment with ramipril. Only the systolic blood pressure after treatment with enalapril was significantly different from the value after treatment with placebo $(p<0.05)$.

The mean baseline plasma urea and creatinine concentrations $(6 \cdot 1(0 \cdot 5) \mathrm{mmol} / \mathrm{l}$ and $98.3(3 \cdot 7) \mu \mathrm{mol} / \mathrm{l}$ respectively) did not change significantly after treatment with enalapril, ramipril, or placebo. Mean plasma angiotensin converting enzyme activity was $2 \cdot 2$ $(0 \cdot 2) \mathrm{mmol} / \mathrm{l} / \mathrm{h}$ before the study and was unchanged by placebo but fell significantly to $1 \cdot 3(0 \cdot 1) \mathrm{mmol} / \mathrm{l} / \mathrm{h}$ after treatment with enalapril and to $0 \cdot 4(0 \cdot 1) \mathrm{mmol} / \mathrm{l} / \mathrm{h}$ after treatment with ramipril. The angiotensin converting enzyme activity after treatment with ramipril was significantly lower than that after treatment with enalapril $(\mathrm{p}<0 \cdot 0001)$.

At the three visits before each treatment was started the mean ( $95 \%$ confidence interval) dose causing at least two coughs was 2.3 (1.3 to 3.4$), 2 \cdot 2$ (1.7 to 2.9 ), and $2.4(1.8$ to $3 \cdot 2)$ nmol capsaicin respectively; the value did not change significantly after treatment with placebo $(2.4(1.5$ to 4.0$) \mathrm{nmol})$ and was $1.8(1.12$ to $2 \cdot 82) \mathrm{nmol}$ after treatment with enalapril and $2 \cdot 2(1 \cdot 7$ to 3.0 ) nmol after treatment with ramipril (fig 2). The mean dose causing at least five coughs was $20 \cdot 2(13.9$ to $29 \cdot 6), 20 \cdot 3(14 \cdot 5$ to $28 \cdot 3)$, and $17 \cdot 6(12 \cdot 0$ to $25 \cdot 8) \mathrm{nmol}$ capsaicin during the three visits before each treatment was started and $18.9(13.9$ to 25.8$) \mathrm{nmol}$ after treatment with placebo (fig 2), $14.4(8.4$ to 24.5$) \mathrm{nmol}$ after treatment with enalapril, and $15 \cdot 3(10 \cdot 8$ to $21 \cdot 18) \mathrm{nmol}$ after treatment with ramipril. None of these changes were significant. The probability of a type 2 error - that is, a change of one dilution of capsaicin being missed was $<0.04$ for the dose causing at least two coughs and $<0.02$ for the dose causing at least five coughs; this was calculated from the variance of the data among the groups at the three visits before each treatment period and after treatment with placebo.

No patient complained of cough during treatment with placebo, but three women (cases 5, 8, and 10) reported cough during treatment with both enalapril

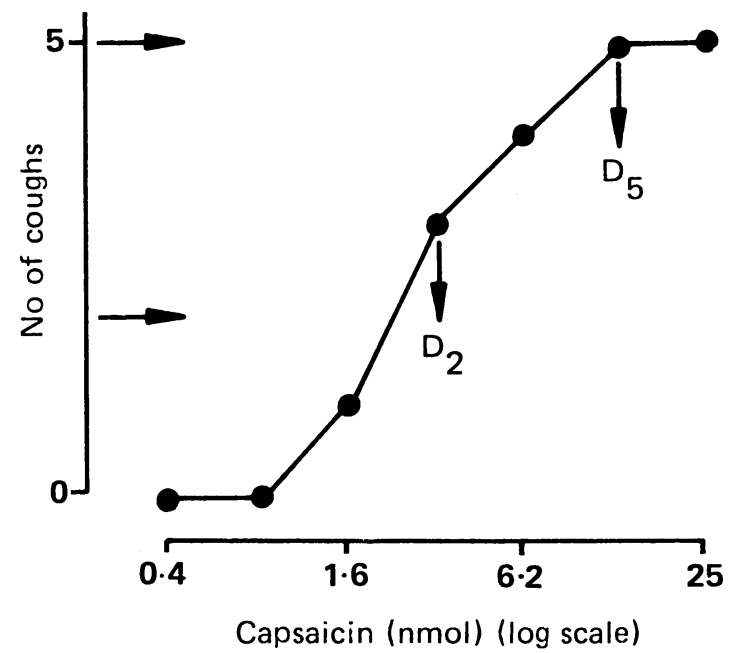

FIG 1-Dose-response curve for typical patient showing doses of capsaicin that caused two or more $\left(D_{2}\right)$ and five or more coughs $\left(D_{5}\right)$ 

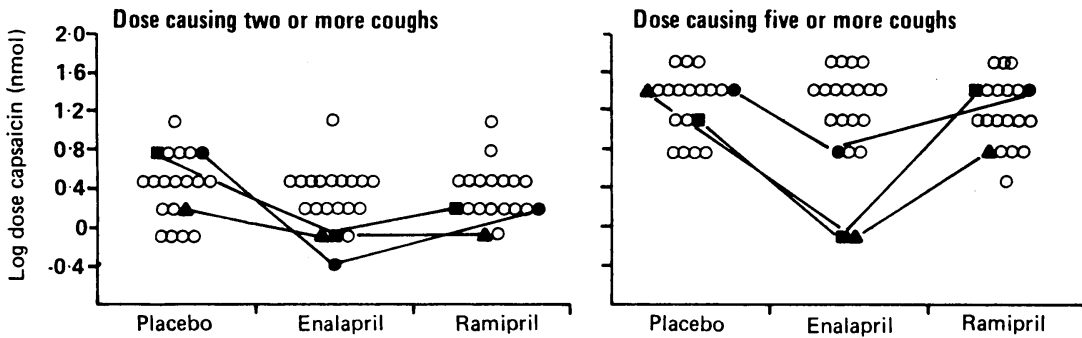

FIG 2-Doses of capsaicin that caused two or more coughs (top) and five or more coughs (bottom) in 20 patients with hypertension after treatment with placebo, enalapril, and ramipril. Values for the three patients who developed cough are shown by solid symbols and ramipril. None of these three patients had any other respiratory symptom. Although all three had a normal sensitivity to capsaicin during treatment with placebo, they each showed a considerable increase in the sensitivity of the cough reflex during treatment with the angiotensin converting enzyme inhibitors (fig 2). After treatment with enalapril two of these patients coughed excessively at the second lowest dose of capsaicin, so that the doses causing at least two and five coughs were the same, and the two doses for each of the three patients fell below the $95 \%$ confidence intervals for the group (the dose causing at least two coughs was $0.8,0.8$, and $0.4 \mathrm{nmol}$ respectively and the dose causing at least five coughs was $0 \cdot 8,0 \cdot 8$, and $6 \cdot 2$ respectively). After treatment with ramipril the dose causing at least two coughs for each of the three patients fell below the $95 \%$ confidence intervals of the group $(0.8,1.6$, and $1.6 \mathrm{nmol}$ respectively), and the dose causing at least five coughs for one of them (case 5) was below the $95 \%$ confidence interval $(6.2 \mathrm{nmol})$; interestingly, the two other patients described the cough during treatment with ramipril (which they received after enalapril) as less severe than that experienced during treatment with enalapril.

There was no correlation between the change in plasma angiotensin converting enzyme activity or blood pressure in response to treatment with enalapril or ramipril and alteration in the sensitivity of the cough reflex.

\section{Discussion}

Cough, whether or not it produces sputum, is often a symptom of respiratory disease and is probably the most common complaint that cäuses patients to visit their doctor. It is a protective reflex, the afferent fibres of which arise in pulmonary stretch receptors, ${ }^{16}$ receptors in the upper airway wall, ${ }^{178}$ and $c$ fibre endings in the mucosa of the larynx, trachea, and bronchi. ${ }^{1920}$ The non-myelinated sensory c fibres, which contain neuropeptides, such as substance $P$ and calcitonin gene related peptide, are stimulated by capsaicin. ${ }^{21 \cdot 23}$

We believe that this is the first prospective placebo controlled study of the effects of treatment with angiotensin converting enzyme inhibitors on the sensitivity of the cough reflex. We found that there was no generalised change in the sensitivity of the cough reflex in all patients given an angiotensin converting enzyme inhibitor but there was a considerable increase in the sensitivity to inhaled capsaicin in three $(15 \%)$ of the patients, and these were the patients who complained of cough during treatment with enalapril and ramipril. They had a normal cough response to capsaicin after treatment with placebo, and thus the cough was not due to an abnormally sensitive reflex before treatment. The incidence of cough as a side effect of treatment with angiotensin converting enzyme inhibitors in this study was at the higher end of the range predicted from retrospective analysis of symptoms. ${ }^{7.9}$ There was no correlation between the sensitivity of the cough reflex and plasma angiotensin converting enzyme activity or blood pressure. It is unlikely that change in the sensitivity of the cough reflex was missed in this study as the probability of a type 2 error was low and a group of only 16 patients would have been required to show a doubling of sensitivity (the smallest change noted in the patients who coughed), represented by the dose causing at least two coughs, and only 14 patients for a change in the dose causing at least five coughs.

The mechanism of increased cough during treatment with angiotensin converting enzyme inhibitors is unknown. A specific effect on the $c$ fibres is difficult to predict because other provocative tests such as inhalation of citric acid are limited by tachyphylaxis. Enalapril potentiates the wheal response to subcutaneous injection of bradykinin, and the increase in blood flow in the forearm during infusion of bradykinin into the brachial artery is potentiated by infusion of enalaprilat, the active metabolite of enalapril. ${ }^{24}{ }^{25}$ This suggests that angiotensin converting enzyme inhibitors affect breakdown of bradykinin and that kinins may have a role in causing the cough. The effect of kinins may not be direct; bradykinin can induce the release of prostaglandins that cause bronchoconstriction in guinea pigs, ${ }^{26}$ and an uncontrolled report has suggested that an inhibitor of cyclo-oxygenase activity may alleviate the cough caused by treatment with angiotensin converting enzyme inhibitors. ${ }^{27}$

Cough is a prominent symptom of some patients with asthma. ${ }^{28} \mathrm{~A}$ high proportion of patients who were reported to have developed cough during treatment with angiotensin converting enzyme inhibitors were asthmatic. ${ }^{511}$ Indeed one study identified a group of patients who coughed during treatment with angiotensin converting enzyme inhibitors and had bronchial hyperreactivity while not receiving the treatment. Their bronchial responsiveness increased during treatment. ${ }^{29}$ This group showed no other changes in dynamic lung function, including peak flow rate. Other workers found, however, that patients with chronic bronchitis treated with enalapril had an increased forced expiratory volume in one second (P Howard et al, International Society of Hematology meeting, Heidelberg, 1986. Abstract 308), and Dixon et al showed that ramipril had no effect on lung function or airway reactivity in patients with mild asthma when they inhaled histamine or bradykinin. ${ }^{30}$ The present study included two patients with asthma, neither of whom had a change in their asthmatic symptoms or developed cough during treatment with enalapril or ramipril. None of the three patients who coughed during treatment developed any symptoms of asthma. We have performed histamine challenges in five patients who presented with cough caused by treatment with angiotensin converting enzyme inhibitors, none of whom had an abnormal response, although all had an abnormal cough reflex (unpublished observation).

The apparent prominence of patients with asthma among those patients who develop cough when taking converting enzyme inhibitors may reflect either high use of the drugs because $\beta$ adrenoceptor blocking drugs in these patients are contraindicated or the interests of chest physicians. In our previous study three of the patients with cough during treatment with angiotensin converting enzyme inhibitors were asthmatic and showed no deterioration in their asthma."

In the present study all of the patients who complained of cough were women. Interestingly, two thirds of reported cases of cough during treatment with angiotensin converting enzyme inhibitors have been in women. ${ }^{31}$ Two of the patients who coughed in this study were smokers, but all had normal responses to the cough reflex after treatment with placebo. It is not clear why only a few patients are affected by this symptom, and our findings do not point to clear differences in the ability of two different angiotensin 
converting enzyme inhibitors to cause cough: the development of cough and the change in the sensitivity of the cough reflex in the three patients occurred with both enalapril and ramipril. Further studies on the sensitivity of the cough reflex in patients taking different angiotensin converting enzyme inhibitors are required. Pharmacokinetic factors and access of the drugs to tissue sites may be important in the development of cough, but, as shown here, the plasma angiotensin converting enzyme activity is not related to blood pressure or the occurrence of cough. In some patients a reduction in the dose of the inhibitor may alleviate the cough (personal observation), but there is no direct evidence of dose dependence of the symptom.

Cough caused by treatment with angiotensin converting enzyme inhibitors will be increasingly important as these drugs are prescribed more widely. Further studies to elucidate the mechanism of this side effect are required and may help to clarify the mechanisms of cough as a symptom of respiratory disease.

This work was supported by grants from the Medical Research Council and Hoechst (UK). We thank Hoechst (UK) for providing the ramipril, enalapril, and placebo capsules; Miss Audrey Douglas for secretarial help; and Drs Neil Pride and Graham Taylor for helpful comments.

1 CONSENSUS Trial Study Group. Effects of enalapril on mortality in severe congestive heart failure. Results of the cooperative north Scandinavian enalapril survival study (CONSENSUS). $N$ Engl F Med 1987;316:1429-35.

2 Sharpe N, Murphy J, Smith H, Hannan S. Treatment of patients with symptomless left ventricular dysfunction after myocardial infarction. Lancet $1988 ; \mathrm{i}: 255-9$.

3 Sesoko S, Kaneko Y. Cough associated with the use of captopril. Arch Intern Med 1985;145: 1524 .

4 Israel-Biet D, Delaisements C, Chretien J. Enalapril-induced cough. Lancet 1986;ii:918.

5 Semple PF, Herd GW. Cough and wheeze caused by inhibitors of angiotensinconverting enzyme. N Engl f Med 1986;314:61.

6 Webb D, Benjamin N, Collier J, Robinson B. Enalapril-induced cough. Lance 1986;ii: 1094 .

7 Coulter DM, Edwards IR. Cough associated with captopril and enalapril. BrMed f 1987;294:1521-3.

8 Strumpe KO, Kolloch R, Overlack A. Captopril and enalapril: evaluation of therapeutic efficacy and safety. Practical Cardiology 1984;10:111-24.

9 Hood S, Nicholls MG, Gilchrist NL. Cough with angiotensin convertingenzyme inhibitors. $N Z$ Med f 1987;100:6-7.
10 Collier JG, Fuller RW Capsacin inhalarion in man and the effects of sodium cromoglycate. Br f Pharmacol 1984;81:113-7.

11 Fuller RW, Choudry NB. Increased cough reflex associated with angiotensin converting enzyme inhibitor cough. Br Med f 1987;295:1025-6.

2 Morice AM, Brown MJ, Lowry R, Higenbottam T. Angiotensin-converting enzyme inhibitors and the cough reflex. Lancet 1987; ;i: 1116-8.

13 Crozier IG, Ikram H, Nicholls MG, Jans S. Acute hemodynamic, hormonal and electrolyte effects of ramipril in severe congestive heart failure. $A m$ Cardiol 1987;59:155-63D.

14 Villamil AS, Cairns V, Witte PU, Bertolasi CA. A double-blind study to compare the efficacy, tolerance and safety of two doses of the angiotensin converting enzyme inhibitor, ramipril with placebo. Am $\mathcal{Y}$ Cardiol 1987 59:110-4D.

15 Friedland J, Silverstein E. A sensitive fluorimeter assay for serum angiotensinconverting enzyme. Am $\mathcal{f}$ Clin Pathol 1976;66:416-24.

16 Hanacek J, Davies A, Widdicombe JG. Influence of lung stretch receptors on the cough reflex in rabbits. Respiration 1984;45:161-8.

17 Widdicombe JG. Receptors in trachea and bronchi of the cat $f$ Physiol (Lond) 1954;123:71-104.

18 Sant'Ambrogio G, Remmers JE, De Groot WJ, Callas CT, Mortola JP. Localisation of rapidly adapting receptors in the trachea and main stem bronchus of the dog. Respir Physiol 1978;33:359-66.

19 Coleridge JCG, Coleridge HM. Afferent vagal c-fibre innervation of the lungs and airways and its functional significance. Rev Physiol Biochem Pharmacol 1984;99:101-10.

20 Sant'Ambrogio G. Afferent pathways for the cough reflex. Bull Eur Physiopathol Respir 1987;23(suppl 10): 19-24S.

21 Wharton J, Gulbenkian S, Mulderry PK, et al. Capsaicin induces a depletion of calcitonin gene-related peptide (CGRP)-immunoreactive nerves in the cardiovascular system of the guinea pig and rat. $\mathcal{J}$ Auton Nero Sys 1986;16:289-309.

22 Coleridge HM, Coleridge JCG, Luck JC. Pulmonary afferent fibres of small diameter stimulated by capsaicin and by hyperinflation of the lungs. $f$ Physiol (Lond) 1965;179:248-62.

23 Szolcsanyi J. A pharmacological approach to elucidation of the role of different nerves and receptor endings in mediation of pain. 7 Physiol (Paris) 1977;73:257-9.

24 Fuller RW, Warren JB, McCusker M, Dollery CT. Effect of enalapril on the skin response to bradykinin in man. Br f Clin Pharmacol 1987;23:88-90.

5 Benjamin N, Cockcroft JR, Collier JG, Dollery CT, Ritter JM, Webh DJ. Local inhibition of converting enzyme and vascular responses to angiotensin and bradykinin in the human forearm. F Physiol (Lond) 1989;412:543-55.

26 Rossoni G, Omini C, Viganot T, Mandelli V, Folco GC, Berti F. Bronchoconstriction by histamine and bradykinin in guinea pigs: relationship to $\mathrm{TXA}_{2}$ generation and the effect of aspirin. Prostaglandins 1980;20:547-57.

27 Nicholls MG, Gilchrist NL. Sulindac and cough induced by" converting enzyme inhibitors. Br Med $\mathcal{F}$ 1987;294:872.

$28 \mathrm{McF}$ adden ER Jr. Exertional dyspnea and cough as preludes to acute attacks of bronchial asthma. N Engl f Med 1975;292:555-9.

29 Bucknall CE, Neilly JB, Carter R, Stevenson RD, Semple PF. Bronchial hyperreactivity in patients who cough after receiving angiotensin converting enzyme inhibitors. BrMed F 1988;296:86-8.

30 Dixon CMS, Fuller RW, Barnes PJ. The effect of angiotensin converting enzyme inhibitor, ramipril on bronchial responses to inhaled histamine and bradykinin in asthmatic subjects. Brf Pharmacol 1987;23:91-3.

31 Berkin KE, Ball SG. Cough and angiotensin converting enzyme inhibition [Editorial]. Br Med f 1988;296:1279.

(Accepted 10 April 1989)

\title{
Accuracy in clinically evaluating pigmented lesions
}

\author{
R K Curley, M G Cook, M E Fallowfield, R A Marsden
}

Departments of

Dermatology and

Histopathology, St

George's Hospital,

London SW17

R K Curley, MD, senior registrar in dermatology M G Cook, MD, consultant histopathologist

M E Fallowfield, MD, senior registrar in histopathology R A Marsden, FRCP, consultant dermatologist

Correspondence to: $\mathrm{Dr}$ Curley.
Abstract

Objective-To determine the ability of three doctors experienced in managing melanocytic lesions to diagnose correctly melanoma, dysplastic naevi, and various benign pigmented lesions.

Design-Independent clinical evaluation and histopathological assessment.

Setting-Pigmented lesion clinic, which patients attend without an appointment for early diagnosis of melanoma.

Patients -86 Patients with lesions that were judged to be benign by at least one of the three doctors.

Interventions-The lesions were excised under local anaesthesia and sent for histopathological examination in coded bottles without clinical details.

Main outcome measure-Comparison of clinical with histopathological diagnosis for each lesion.

Results-A total of 120 lesions were evaluated by at least two of the three doctors. The histopathological diagnoses were made by the same pathologist. The overall sensitivity (diagnostic accuracy) for the three doctors for all types of lesion was $50 \%$. Of the 39 dysplastic naevi, only 19 were identified correctly by all observers, and a further 24 banal lesions were wrongly diagnosed as dysplastic by at least one doctor. Particular difficulty was experienced with small $(<5 \mathrm{~mm})$, flat lesions, which can be banal or potentially malignant.

Conclusions-Critical diagnosis and management decisions concerning pigmented lesions should always be based on a combination of clinical and histopathological assessments and the history of the patient.

\section{Introduction}

The risk of malignant melanoma is increased in people with large numbers of melanocytic naevi ${ }^{12}$ and in those with the dysplastic naevus syndrome. ${ }^{3}$ Previous studies have assumed that benign melanocytic naevi can be distinguished from other banal pigmented lesions such as lentigines and that dysplastic naevi can be recognised on clinical grounds. We tested these assumptions.

\section{Subjects and methods}

We examined 120 pigmented lesions from 86 patients who presented mainly to the pigmented lesion clinic at 